\title{
HYDROLOGIC ASSESSMENT OF WOODY BIOMASS REMOVAL FOR BIOFUEL PRODUCTION
}

\author{
C. TAYLOR SMITH ${ }^{1}$, MICHAEL BARBER $^{1} \&$ ROBERT MAHLER $^{2}$ \\ ${ }^{1}$ Civil and Environmental Engineering, University of Utah, USA \\ ${ }^{2}$ Soil Science Division, University of Idaho, Moscow, ID, USA
}

\begin{abstract}
Wood-based energy markets have been proposed as a means to ensure sustainable forests, enhance energy security, promote environmental quality and realize social benefits. An important issue among stakeholders is that collecting small-diameter woody biomass may significantly alter the water budget of post-timber harvesting landscapes. However, little is actually known about the hydrologic impacts that additional biomass removal and post-harvest land treatments may have on the water budget. Climate data and volumetric water content measurements at depths of 10,20,30 and $100 \mathrm{~cm}$ were collected from 28 one-acre plots near Eugene, OR, USA, subject to seven different land treatments. This information was analysed and used to calibrate and validate a site-specific water balance model (UNSAT-H) to evaluate a null hypothesis that changes in biomass removal do not impact subsurface environment. Results showed a positive correlation between post-harvest land treatments involving soil compaction and evaporation with compacted sites producing over $30 \%$ more evaporation than non-compacted, harvested sites and 20\% more than non-compacted, non-harvested sites. Furthermore, non-compacted sites subject to increased biomass removal had higher infiltration rates than both unharvested sites and harvested, compacted sites. In terms of changes to runoff and sediment production, maximum impact coincides with the period immediately after track construction and harvesting. However, these effects decrease significantly over the 5-year time frame, well within the inter-logging cutting cycle of $30-40$ years in this region.

Keywords: evapotranspiration, sustainable fuels, water balance
\end{abstract}

\section{INTRODUCTION}

Sustainable production of bioenergy is necessary to meet future worldwide energy demands while helping to offset the global impacts of increased carbon dioxide from traditional fossil fuels [1-4]. Sustainability, the ability to meet the present needs without compromising the ability to meet the needs of the future, continues to gain attention as human population growth creates ever-greater pressure on diminishing natural resources [5]. According to the 2016 Federal Activities Report on the Bioeconomy released on February 2016, the Biomass R\&D Technical Advisory Committee has recommended 'targeting a potential 30\% penetration of biomass carbon into the U.S. transportation market by 2030'. Recently, scientists have been researching ways to produce bioenergy without adversely impacting food, land and other environmental resources. The Northwest Advanced Renewables Alliance (NARA), a broad alliance of private industry and educational institutions, takes a holistic approach to building a supply chain within WA, OR, ID and MT based on using forest residuals to make aviation biofuel. NARA's objective is to increase efficiency for each supply chain step from forestry operations to conversion processes, creating new bio-based products; providing economic, environmental and social sustainability analyses; engaging stakeholder groups; and improving bioenergy literacy for students, educators, professionals and the general public. Forest residuals from logging operations will be used as feedstock to fulfil the project aims of creating a sustainable industry to produce aviation biofuels and important co-products.

This portion of the investigation is responsible for assessing the hydrologic concerns of the water balance and is part of a larger effort by the sustainability measurement. Our study 
is aimed at examining the potential hydrologic repercussions of incremental woody biomass removal associated with various degrees of residual ground cover (or biomass) removal in the production of biojet fuel in the Pacific Northwest. The specific region of interest for this project is the vadose zone of the subsurface as net changes to groundwater recharge could create issues with critical base flow during drier parts of the year. To achieve the project goal, completion of three objectives was required:

1) Collect and process data measured at the test plots and develop a predictive water quantity model to evaluate site-scale regional impacts of small-scale biomass removal.

2) Evaluate if there is a correlation between differences in land cover as a function of unique soil characteristics, such as cation exchange capacity (CEC), clay content percentage, soil carbon percentage, slope of the land, microbial population, $\mathrm{pH}$ and electric conductivity.

3) Determine the capability of extending site-scale regional impacts of small-scale biomass removal to watershed-scale semiarid regional impacts of large-scale biomass removal.

These objectives helped quantify the effects of woody biomass removal on the soil and water balance of the study site, and therefore demonstrate the sustainability of harvesting woody biomass forest residuals as a source of biomass for the NARA bioenergy feedstock. The vadose zone groundwater model was calibrated using on-site measured values of volumetric water content (VWC) over time, and calculated for the infiltration/evaporation water budget values.

\section{BACKGROUND}

It has been previously stated that very severe compaction at high moisture contents causes soil deformation, thus decreasing soil water potential [6]. Furthermore, it's been studied previously that compaction impairs the conditions of the soil by increased soil bulk density, increased nitrification rates, reduced porosity and water infiltration rates, damaged soil structure and aggregate stability [5]. In some soils, even small deformations can cause large decreases in the saturated hydraulic conductivity of that particular soil. Therefore, the three study objectives described earlier will be evaluated using the following null hypotheses:

i) $\mathrm{H}_{0}$ : Increased biomass removal from the Long-Term Soil Productivity (LTSP) site will have no impact on infiltration rates or the water budget of the subsurface.

ii) $\mathrm{H}_{0}$ : There is no distinction between differences in land cover as a function of unique soil characteristics such as slope, saturated conductivity, soil temperature, CEC and microbial populations present.

iii) $\mathrm{H}_{0}$ : Data from the site-scale regional impacts can be applied to watershed-scale regional impacts of large-scale biomass removal through the Pacific Northwest.

As a part of Weyerhaeuser's effort to sustainably manage its more than 6 million acres of forested timberland in the United States, it continues to conduct, evaluate and support research associated with the North American LTSP programme. Data for this investigation were collected from Weyerhaeuser's LTSP site in the southern Willamette Valley near Springfield, Oregon, in the Pacific Northwestern United States. The site was created to support the NARA project. A total of 28 one-acre plots were selected to aid in this investigation and round out an existing regional study, to extend into warmer and drier parts of the Douglas-fir ranges, 


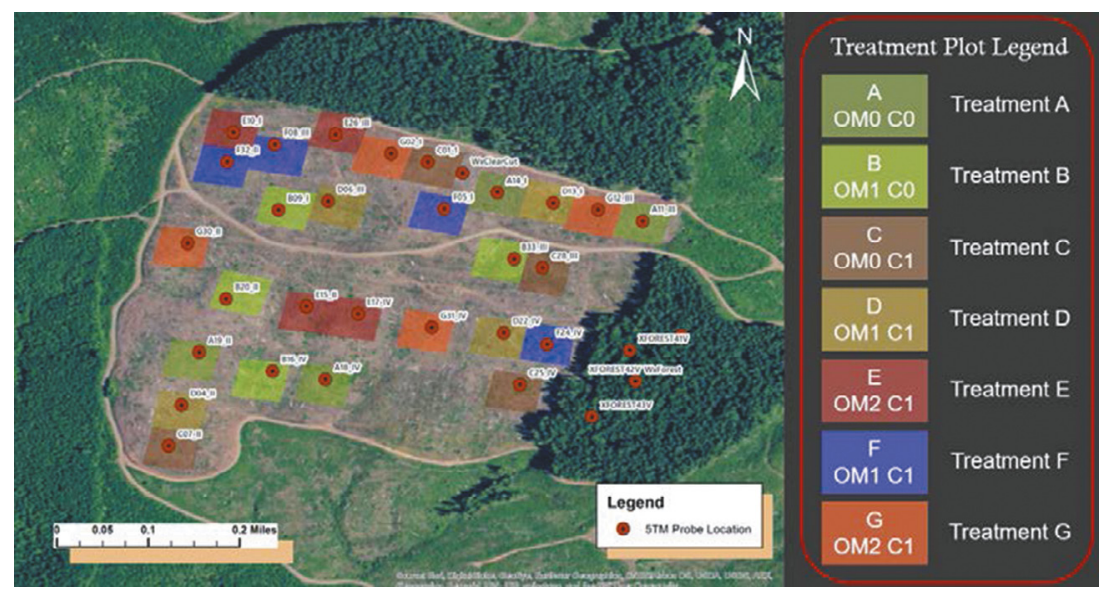

Figure 1: ArcMap model of LTSP study plots and location of soil moisture probes [7].

as to contribute more understanding into the broader LTSP network. Treatments were randomly assigned and laid out in such a way that any plot could feasibly receive that particular random assignment (see Fig. 1). These plots are part of a larger interconnected network for hydrologic analysis. The site elevation is between 600 and $670 \mathrm{~m}$ above the mean sea level on gentle slopes of 2-20\%. Soil information was collected from Weyerhaeuser's NARA LTSP plot summary analysis. The majority of the information used to characterize the soil class were the percent silt, percent sand and percent clay values, CEC, carbon organic matter amount, $\mathrm{pH}$ and electric conductivity.

The average annual precipitation at the study site is $129.3 \mathrm{~cm}\left(50.9^{\prime \prime}\right)$. Summers tend to be dry with less than one-third that of the wettest winter month, and with less than $3.9 \mathrm{~cm}$ $\left(1.54^{\prime \prime}\right)$ of precipitation in a summer month. The month with the most precipitation on average is November with $21.4 \mathrm{~cm}\left(8.44^{\prime \prime}\right)$ of precipitation. The month with the least precipitation on average is July with $1.6 \mathrm{~cm}\left(0.64^{\prime \prime}\right)$ of precipitation. The warmest month, on average, is August with an average temperature of $27.8^{\circ} \mathrm{C}\left(82^{\circ} \mathrm{F}\right)$ and the coolest month on average is December, with an average temperature of $7.8^{\circ} \mathrm{C}\left(46^{\circ} \mathrm{F}\right)$.

Multiple studies provide evidence that forest-harvesting practices undoubtedly have a significant effect upon surface soil properties, and in semi-arid regions where the clearing of land promotes desertification [8]. In rain-dominated portions of the Pacific Northwestern United States, annual water yield may be enhanced by the removal of forest vegetation from small upland watersheds, yet questions still remain regarding the effects of logging operations on infiltration under the variety of climatic, physiographic and vegetative conditions of this region. The objective of this study was to examine the ecological environment through the measurement of soil moisture at the site and develop a predictive water quantity and quality models based on each different types of removal $(A-G)$.

\section{METHODOLOGY}

The plots shown in Fig. 1 represent the General LTSP 'Core' treatments consisting of a $3 \times 2$ factorial combination of compaction ( $\mathrm{C} 0$, none; $\mathrm{C} 1$, moderate) and aboveground $\mathrm{OM}$ removal (OM0, bole/trunk only; OM1, whole tree; OM2, whole tree plus forest floor removal). Three levels of organic matter removal and two levels of compaction in a $3 \times 2$ complete factorial 
Table 1: Tabular form of treatment removal technologies.

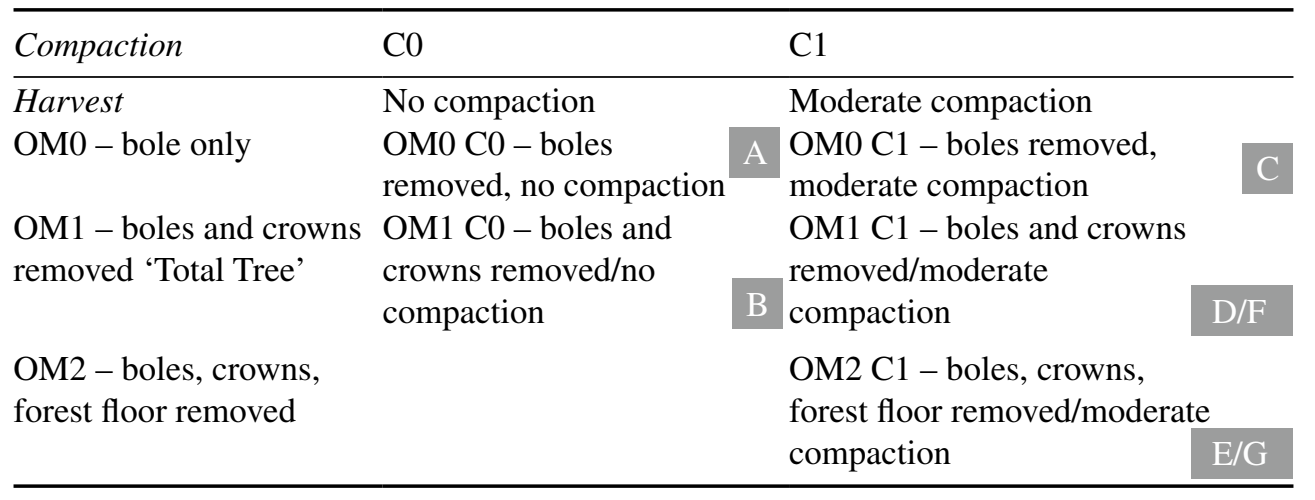

design exist - totalling seven different treatment plots. Multiple passes with heavy machinery were used to compact soils. Seven different treatment combinations have been applied to 28 study plots, four replicate plots of each treatment. The different treatment types based on two different levels of compaction and three different levels of biomass land cover are categorized as follows, and presented via tabular form in Table 1, with their designated treatment type denoted by the letter in the top right corner. Additionally, Fig. 1 depicts each LTSP study plot location on the ArcMap model, including the location of the soil moisture sensor probes and weather stations.

The following is an explanation of the terminology used in Table 1:

C0 - No compaction - no ground trafficking on plot.

$\mathrm{C} 1$ - Compaction - fixed traffic lanes where plot is levelled with forestry machinery.

OM0 - Boles only - boles/trunks only, meaning harvest consists in removing saw log top (5" minimum diameter), while all other limbs and tops remain on the site.

OM1 - Total Tree - whole-tree-type harvest where approximately $75+\%$ of limb/top material is removed along with boles/trunks. Remaining material will be dispersed equally across plots.

OM2 - Total Tree + forest floor - whole-tree-type harvest where $~ 90-95 \%$ of limb/top material is removed along with the bole/trunk. Forest floor and legacy woody debris also removed.

A typical example of the LTSP plots after woody biomass removal is shown in Fig. 2. Note the clearly visible compaction tracks caused by harvesting activities. These tracks are quickly obliterated by the time the saplings were planted a year later.

The objectives of this study were completed by collecting the necessary weather and soil characteristics data. The mean absolute error (MAE) was calculated for each plot for each season of the year over the course of 2 years between its measured and simulated values. UNSAT-H Version 3.0: Unsaturated Soil Water and Heat Flow Model, developed by the Pacific Northwest National Laboratory for the United States Department of Energy, will be used to develop a predictive water balance model that correlates with data collected from the soil moisture probes installed in the field. The kind of information that will then be predicted from the model will be quantified amounts of runoff, infiltration, evaporation and overall water balance. 


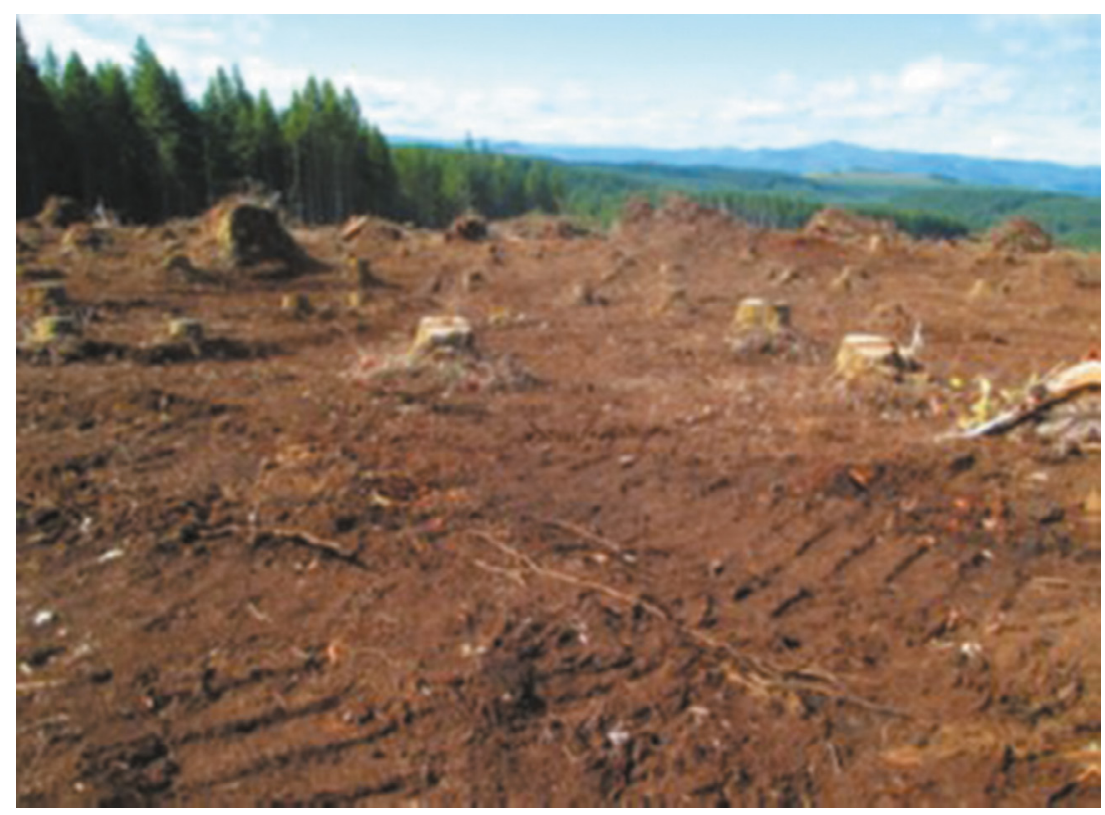

Figure 2: LTSP site for treatment G: (OM2 C1) compaction total tree + FF [7].

Approximately four soil moisture measurement probes were installed at each plot location on the map, respectively, totalling to approximately 112 probes for the whole LTSP site. The 5TM Soil Moisture \& Temperature Sensor by Decagon Devices $®$ was the chosen soil moisture and temperature probe selected for installation. Weyerhaeuser conducted the seven different land alterations at each plot, and installed four separate sensors at 10, 20, 30 and $100 \mathrm{~cm}$ depths, respectively. For the 10, 20 and $30 \mathrm{~cm}$ depths, a trench wall was dug and the sensors were installed with a horizontal orientation to the surface. For the $100 \mathrm{~cm}$ depth, an auger hole was drilled into the subsurface and the sensors were installed with a vertical orientation to the surface. In three locations, the $100 \mathrm{~cm}$ depth was too grave to install a 5TM sensor, therefore not collecting data at the $100 \mathrm{~cm}$ depth. Additionally, there are two weather stations installed at the sites to measure precipitation, air temperature, wind speed, relative humidity and solar radiation at every hour. One weather station is in the clear-cut section, and the other weather station is located in the forested section. An example of the data generated is shown in Fig. 3.

An unsaturated flow recharge model (UNSAT-H) was used to estimate infiltration and evaporation of the groundwater and also helped predict water drainage rates for the simulated conditions. UNSAT-H is a one-dimensional vertical or horizontal model which uses the finite difference method to solve for Richard's equation [9]. There are many soil water retention relationships that have been determined, such as the linked polynomials, the Haverkamp function, the Brooks and Corey function, the van Genuchten function and several special functions that account for water retention of very dry soils [10]. Therefore, eqn (1) illustrates how water content and hydraulic conductivity are functions of suction head according to the van Genuchten function and Mualem hydraulic conductivity model and has the form 


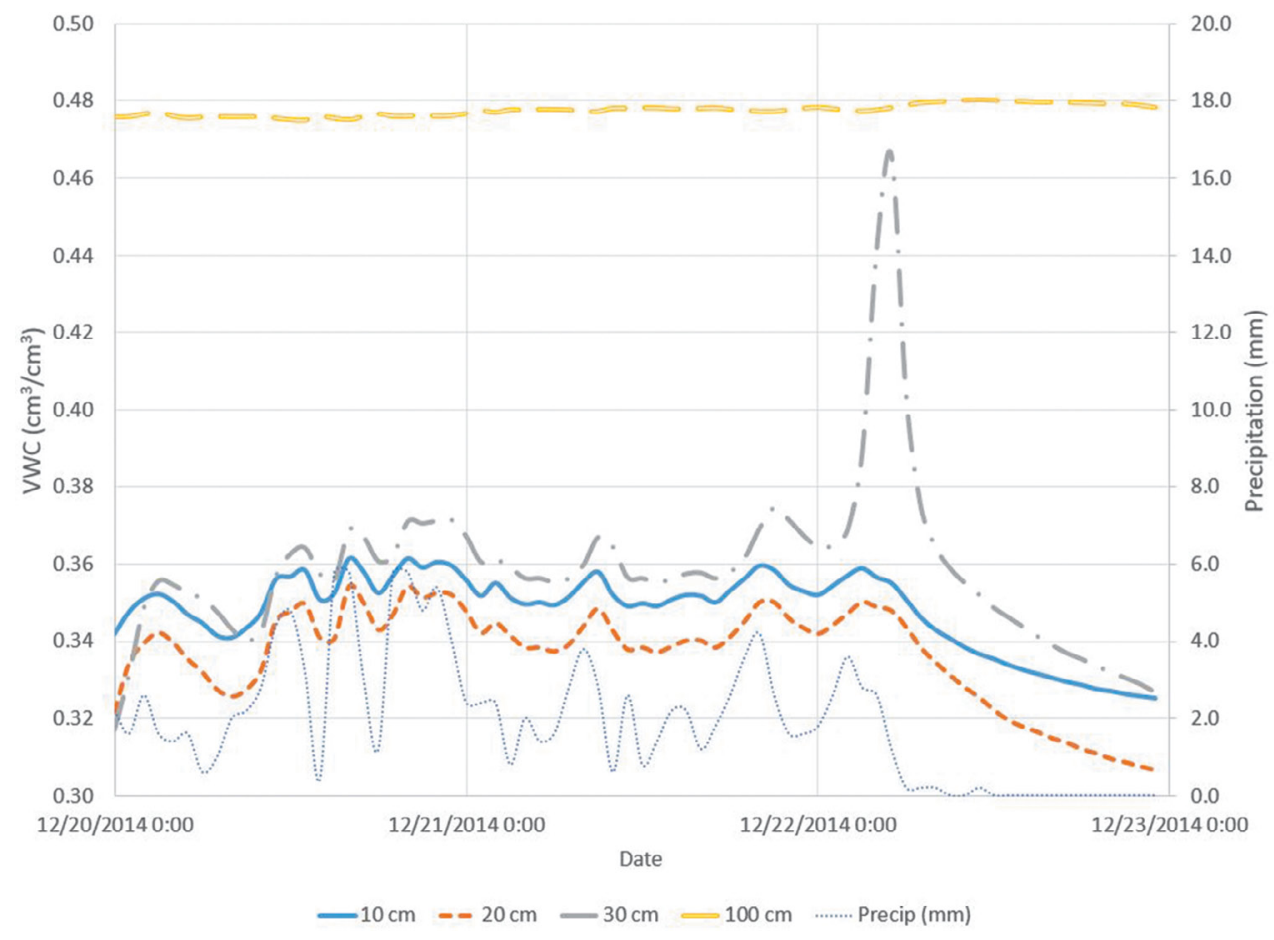

Figure 3: Treatment plot F08III VWC during peak rainfall event in December 2014 [7].

$$
\theta=\theta_{\mathrm{r}}+\left(\theta_{\mathrm{s}}-\theta_{\mathrm{r}}\right)\left[1+(\alpha h)^{n}\right]^{-m}
$$

where the parameters $\alpha, m$ and $n$ are curve-fitting parameters based on soil type, and it is assumed that $m=1-1 / n . \theta_{\mathrm{r}}$ is the residual water content and $\theta_{\mathrm{s}}$ is the saturated water content. The conductivity function is based on the Mualem conductivity model [11] shown in eqn (2):

$$
K_{\mathrm{L}}=K_{\mathrm{s}} \frac{\left(1-(\alpha h)^{n-2}\left[1+(\alpha h)^{n}\right]^{-m}\right)^{2}}{\left.\left[1+(\alpha h)^{n}\right]^{-m}\right)^{2}}
$$

where $K_{\mathrm{L}}$ is the unsaturated hydraulic conductivity and $K_{\mathrm{S}}$ is the saturated hydraulic conductivity.

Both statistical and graphical model techniques were reviewed for the calibration of the UNSAT-H simulations. For graphical techniques, curve fitting to simulate the measured data at the LTSP site for each respective plot as closely as possible for the changes in water content over time was used. For statistical model techniques, the MAE and percent bias (PBIAS) values were calculated between the observed and simulated values of water content at each given day. The constraining statistic model technique used for this study was PBIAS, and this measures the average tendency of the simulated data to be larger or smaller than their observed water content counterparts. The optimal value of PBIAS is 0.0, with low-magnitude values indicating accurate model simulation. Positive values indicate model underestimation bias, and negative values indicate model overestimation bias [12]. The reported performance ratings and corresponding values developed were adapted from the work of Moriasi [13] and include ranges of values used in establishing general performance which appear in Table 2. 
Table 2: General performance ratings for recommended statistics.

\begin{tabular}{ll}
\hline Performance rating & PBIAS $(\%)$ \\
\hline Very good & PBIAS $< \pm 10$ \\
Good & $\pm 10 \leq$ PBIAS $< \pm 15$ \\
Satisfactory & $\pm 15 \leq$ PBIAS $< \pm 25$ \\
Unsatisfactory & PBIAS $\geq \pm 25$ \\
\hline
\end{tabular}

Performance was evaluated on the results of the simulation by calculating the MAE and PBIAS values and can be found in Table 2. A 'satisfactory' rating between $\pm 15 \%$ and $\pm 25 \%$ was preferred; therefore, multiple iterations of parameter changes were made until PBIAS values were under $\pm 25 \%$.

\section{RESULTS AND DISCUSSION}

Two-year simulations with the UNSAT-H model were completed for each of the 28 treatment plots. Time-series graphs for two typical simulations with respective VWC measurements $(\theta)$ are shown later. Figures 4 and 5 illustrate both variations in depth and seasonal variation in moisture content. Summer drainage and evaporation are clear in the near-surface model predictions.

The total basal liquid flux (drainage) was defined as the amount of water that penetrates the water table. Once the water has travelled this vertical distance below the subsurface, it is assumed to have infiltrated the water table and thus impact the water budget. Total infiltration was defined as the total amount of water that penetrates the water table located at $150 \mathrm{~cm}$. Any amount of water that resides above the water table, which includes the current water moisture in the $0-150 \mathrm{~cm}$ soil profile, is considered as 'total infiltration'.

UNSAT-H: Spring 2014 - 2016 Treatment E10I with Precipitation

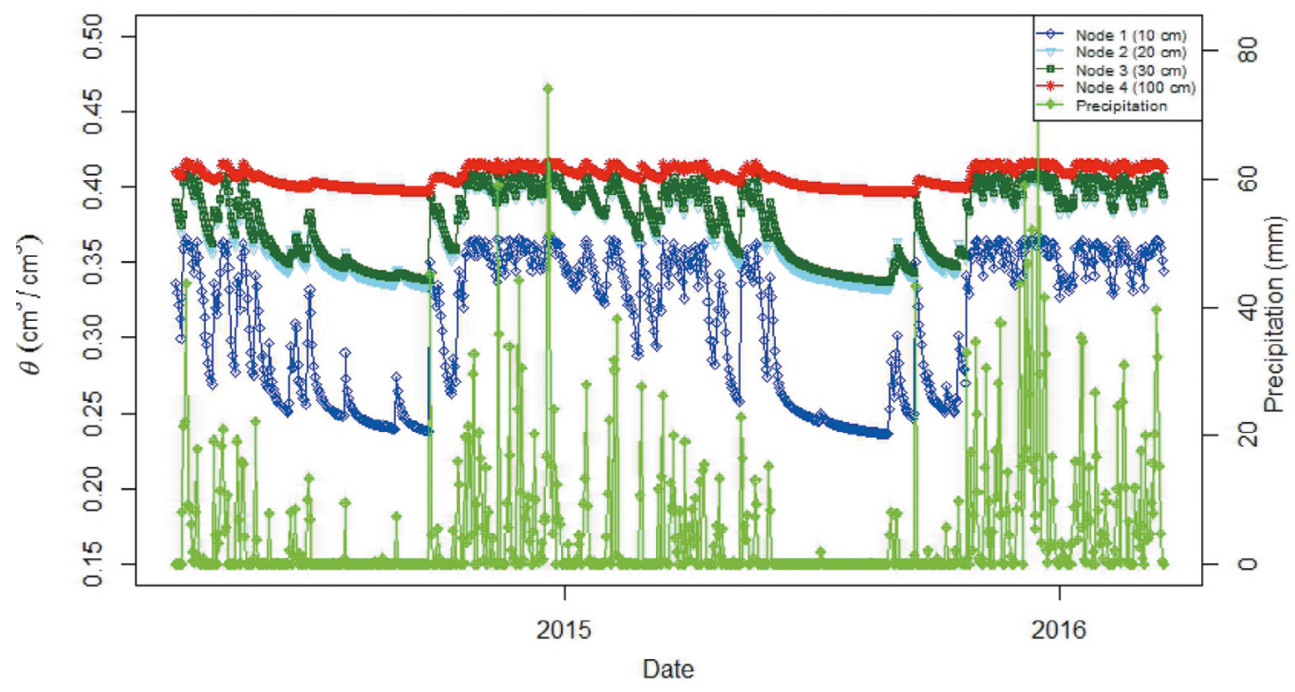

Figure 4: Volumetric water content and precipitation for treatment plot E10I. 
UNSAT-H: Spring 2014 - 2016 Treatment G02I with Precipitation

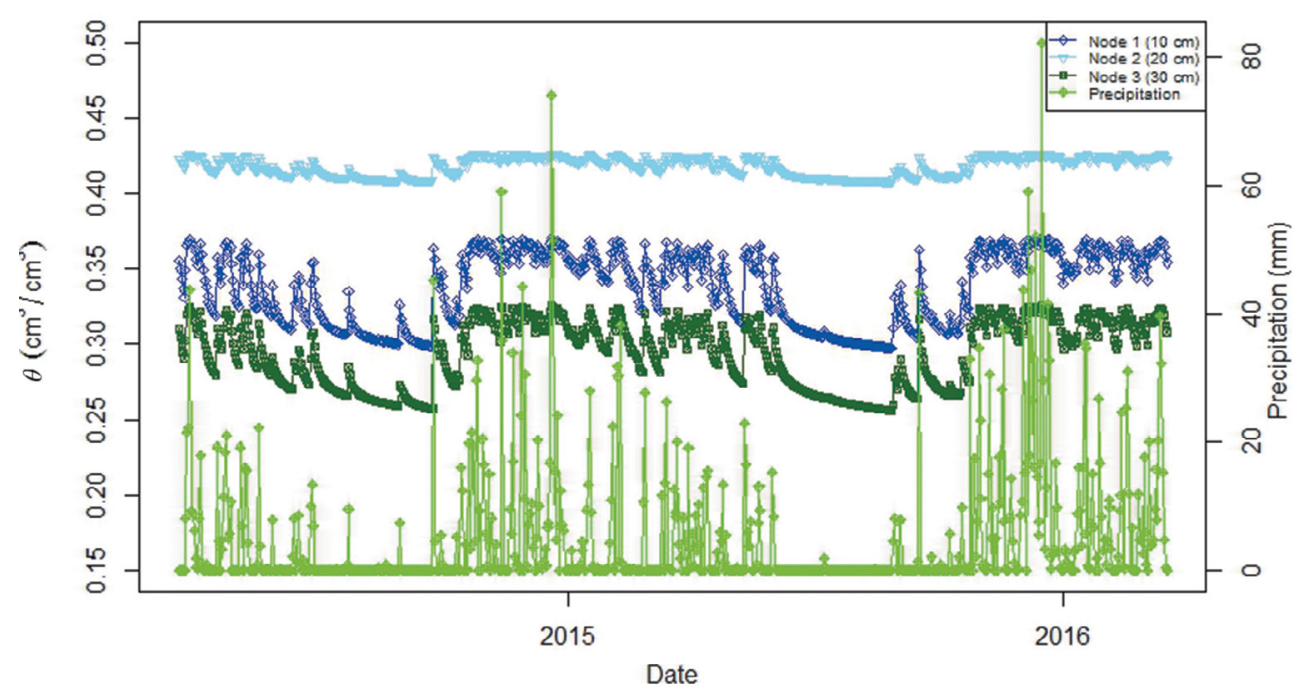

Figure 5: Volumetric water content and precipitation for treatment plot G02I.

After the analysis of the amount of evaporation from each treatment type A-G, it was observed that there were statistically higher evaporation rates in treatments $\mathrm{C}-\mathrm{F}$ when compared with treatments A-B, ranging from $12 \%$ to $32 \%$ increase. Treatments D-F fall in the $\mathrm{C} 1$ compaction category, as well as the OM1 and OM2 harvest categories. To investigate why the compacted sites had more evaporation, an infiltration analysis was conducted between a non-compacted plot, A19II, with a compacted plot, F08III. These two plots had similar soil types in the subsurface when compared with one another, and therefore chosen for this infiltration analysis. A peak rainfall event was chosen to ensure a significant response in VWC changes. The peak rainfall event occurred on 20 December 2014 for a total of $7.4 \mathrm{~cm}$ of rainfall and continued on 21 December 2014 for a total of $5.14 \mathrm{~cm}$ of rainfall. The last day observed was 22 December 2014 with a total rainfall amount of $1.54 \mathrm{~cm}$, bringing the total rainfall over the course of 3 days to $14.08 \mathrm{~cm}$ of precipitation. Hourly VWC values were plotted at each port location, 10, 20,30 and $100 \mathrm{~cm}$, respectively, with precipitation on the secondary axis. For plot A19II, there is a substantial increase in VWC before the main portion of the storm occurs. Possible sources of error could have risen from measurement error of the $5 \mathrm{TM}$ sensor at $100 \mathrm{~cm}$. Additionally, percent change values were calculated from the daily average VWC values for each port location. A positive percentage change in VWC denotes an increase, meaning the soil is gaining water, while a negative percentage change in VWC denotes a decrease, meaning the soil is losing water. Figure 6 shows the results for A19II plot compared to the F08III results previously shown in Fig. 3.

Statistically it was shown that our first hypothesis suggesting that land treatments did not impact evaporation was false. Removal of biomass without compacting soils resulted in considerably more infiltration and less evaporation than compacted soils. However, it was not possible to reach a definitive conclusion for our second hypothesis. Three regression analyses were done for different hydrologic parameters for the three soil profiles conducted by Weyehaeuser during the 5TM sensor installation and soil analysis: 0-15, 15-30 and 30-100 cm. 


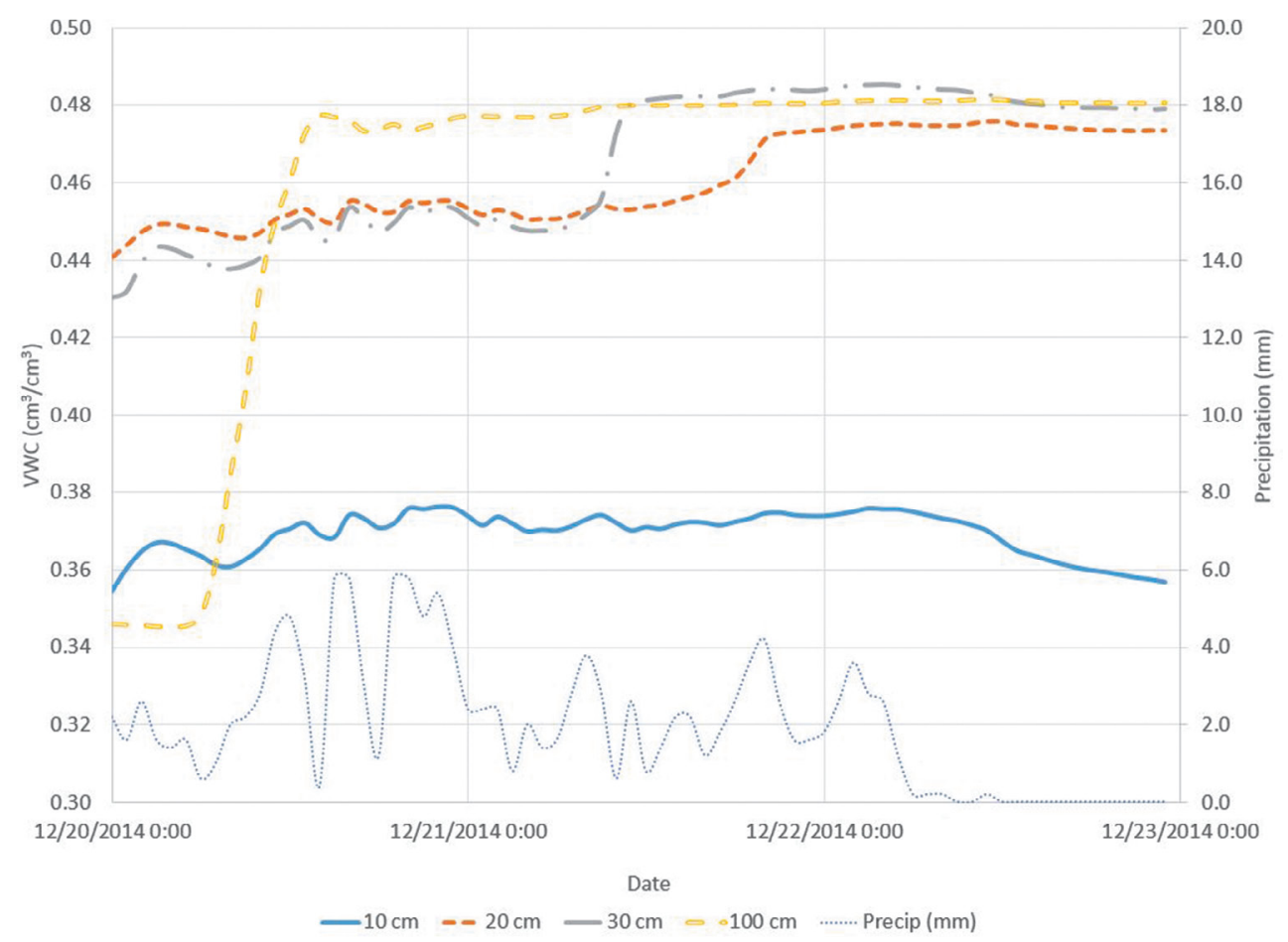

Figure 6: Water content for peak rainfall event for treatment plot A19II.

When the bin depth went across the $30 \mathrm{~cm}$ 5TM sensor, the two different values were averaged together to receive the $30 \mathrm{~cm}$ designated value. The statistical results for the analysis of each soil profile for total basal liquid flux drainage simulated values versus percent clay content percentage, $\mathrm{pH}$, electrical conductivity (EC), CEC, soil carbon content in megagrams per hectare (SoilC), mean slope, saturated hydraulic conductivity, average temperature, the five major genus of bacteria present (Bacillus, Clostridium, Shewanella, Thermoanaerobacter and Lactobacillus) were calculated. There was no clear defining distinction between the land cover applications when comparing it with the plot's unique soil characteristics. While it is true that most of the sites contained loams, clay loams and clays, each plot had a different soil composition at each respective subsurface depth.

Our third hypothesis (data from the site-scale regional impacts can be applied to watershedscale regional impacts of large-scale biomass removal through the Pacific Northwest) proved equally difficult to statistically prove. The data varied too much from treatment to treatment so the logical conclusion was that site critical information would be needed for each location where harvesting was proposed.

\section{CONCLUSIONS AND RECOMMENDATIONS}

Soil water evaporation coupled with infiltration and drainage can significantly affect soil water contents and moisture redistributions. UNSAT-H was used to model soil conditions and ground cover options for each of the 28 one-acre sites in the Oregon LTSP. Model results were compared to field measurements of soil moisture taken at four depths. Changes to surface runoff and sediment production due to erosion coincided with the period immediately 
after track construction and harvesting but these effects quickly decreased during our study and were not seen as a significant factor in the water budget analyses. Overall, statistically significant differences in evaporation were observed when compacted soil sites were compared with non-compacted sites. Evidence from the UNSAT-H modelling indicated that compacted sites will exhibit more evaporation from the surface. Furthermore, sites without compaction and with crowns removed exhibited the least amount of evaporation. It is recommended that the woody biomass removal includes crowns to ensure the least amount of evaporation occurs as to disrupt the water budget of the site the least. A statistically significant relationship between soil hydrologic parameters and drainage values to the water table could not be determined. Harvesting operations for biofuel production are therefore advised not to compact the sites but to remove the slash and crowns present at the plot to have the least amount of impact on the water budget of the site.

Future studies on this project are possible, and include plant modelling within the UNSAT$\mathrm{H}$ on the LTSP site to see if and how regrowth of the Douglas Fir saplings affect the water budget, and researching more into drainage rates to other treatment technologies and procedures other than solely the soil hydrologic parameters.

\section{ACKNOWLEDGEMENTS}

This work was supported by the National Institute of Food and Agriculture, U.S. Department of Agriculture. Any opinions, findings, conclusions or recommendations expressed in this publication are those of the author(s) and do not necessarily reflect the view of the U.S. Department of Agriculture.

\section{REFERENCES}

[1] Berndes, G., Bioenergy and water-the implications of large-scale bioenergy production for water use and supply. Global Environmental Change, 12(4), pp. 253-271, 2002. DOI: 10.1016/S0959-3780(02)00040-7.

[2] Johansson, D.J.A. \& Azar, C., A scenario based analysis of land competition between food and bioenergy production in the US. Climatic Change, 82, pp. 267-291, 2007. DOI: 10.1007/978-94-009-0129-2_9.

[3] Beringer, T., Lucht, W. \& Schaphoff, S., Bioenergy production potential of global biomass plantations under environmental and agricultural constraints. GCB Bioenergy, 3, pp. 299-312, 2011. DOI: 10.1016/j.enpol.2009.05.029.

[4] Aransiola, E.F., Ojumu, T.V., Oyekola, O.O., Madzimbamuto, T.F. \& Ikhu-Omoregbe, D.I.O., A review of current technology for biodiesel production: State of the art. Biomass and Bioenergy, 61(2), pp. 276-297, 2014. DOI: 10.1016/j.biombioe.2013.11.014.

[5] Mann, L. \& Tolbert, V., Soil sustainability in renewable biomass plantings. AMBIO: A Journal of the Human Environment, 29(8), p. 492, 2000. DOI: 10.1579/0044-7447-29.8.492.

[6] Soane, B. D. \& Ouwerkerk, C.V., Soil compaction in crop production. Elsevier: Amsterdam, 1994.

[7] Smith, C.T., Evaluating the hydrological impact of removing woody biomass for biofuel production through unsaturated zone modeling. Master of Science Thesis, University of Utah: Salt Lake City, UT, 2017.

[8] Bonan, G.B., Frost followed the plow: Impacts of deforestation on the climate of the United States. Ecological Applications, 9(4), p. 1305, 1999. DOI: 10.1029/95JD02169.

[9] Benson, C., Modeling unsaturated flow and atmospheric interactions. Theoretical and Numerical Unsaturated Soil Mechanics, ed. T. Schanz, Springer: Berlin, pp. 187-202, 2007. 
[10] Fayer, M., UNSAT-H Version 3.0: Unsaturated Soil Water and Heat Flow Model. Pacific Northwest Laboratories: Richland, WA, 2000.

[11] Mualem, Y., A new model for predicting the hydraulic conductivity of unsaturated porous media. Water Resources Research, 12, pp. 513-522, 1976. DOI: 10.1029/ WR012i003p00513.

[12] Gupta, H.V., Sorooshian, S. \& Yapo, P.O., Status of automatic calibration for hydrologic models: Comparison with multilevel expert calibration. Journal of Hydrologic Engineering, 4(2), pp. 135-143, 1999. DOI: 10.1061/(ASCE)1084-0699(1999)4:2(135).

[13] Moriasi, D.N., Arnold, J.G., Van Liew, M.W., Bingner, R.L., Harmel, R.D. \& Veith, T.L., Model evaluation guidelines for systematic quantification of accuracy in watershed simulations. Transactions of the ASABE, 50(3), pp. 885-900, 2007. DOI: $10.13031 / 2013.23153$. 